\title{
Multi-Pronged Approach to the Management of Twisted Ovarian Cysts where Ovarian Conservation is a Matter of Life and Death - Review Article
}

\author{
Dr. Shalini Mahana Valecha ${ }^{1}$, Dr. Vinit Dhakde ${ }^{2}$, Dr. Shrikant Dhumale ${ }^{3}$ \\ ${ }^{1} \mathrm{MD}$, DGO, FGO, FICOG, MBA (Health Care Russia), ${ }^{2} \mathrm{MS}$ OBGY, ${ }^{3}$ Junior Resident \\ Director Professor and Unit Head, Department of OBGY, ESI-PGIMSR, MUMBAI
}

\begin{abstract}
Ovarian torsion is a rare gyna ecological emergency that may elude diagnosis leading to delayed operative intervention and ovarian resection. Wereporta30yearold female who presented with acute one-sided abdominal pain whose diagnosis was missed by the emergency physician resulting in loss of the ovary. The surgery was performed by the gynaecologist laparoscopically.
\end{abstract}

Keywords: abdominal pain, torsion, ovariopexy, laparoscopy

\section{Introduction}

Ovarian torsion is a rare gynaecological emergency that may elude diagnosis leading to delayed operative intervention and ovarian loss. The patient usually suffers from symptoms for 3 days and the diagnosis is usually at surgery ${ }^{1}$.

A 30 year old patient P $1 \mathrm{~L} 1$, with previous LSCS, came with complaints of pain in abdomen since 5 months, dull aching continuous type of pain.

- Past History: Patient had history of right salphingoophrectomy done one year back in view of multiple cyst in right ovary with ovarian torsion.

- On Examination: Vitals stable

- Per Abdomen: soft, non tender, no guarding, no rigidity

- Per Speculum: cervix healthy, vagina healthy

- Per Vaginum Examination: uterus normal size, right fornix free, mass of $6 \times 6 \mathrm{~cm}$, with cystic consistency felt in left fornix, associated with tenderness.

- USG: Two simple cysts in left ovary, measuring 5.4 x 4.8 $\mathrm{cms}$ and $4.2 \times 2.7 \mathrm{cms}$ with half turn of torsion of left ovary.

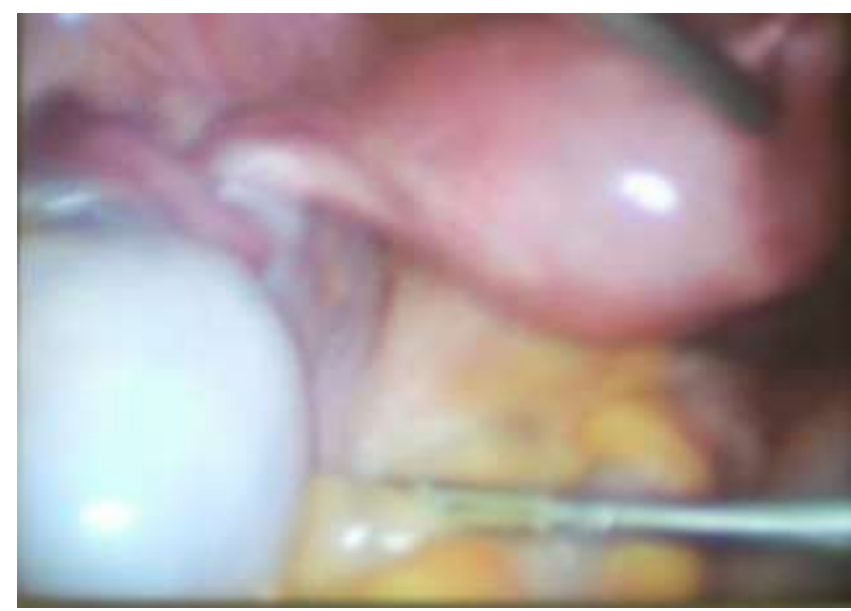

Figure 1: Intraoperative findings

1) Left ovarian cyst $8 \times 6 \mathrm{cms}$ with twisted ovarian pedicle

2) Right ovary and tube not visualized.

3) Long left ovarian ligament.

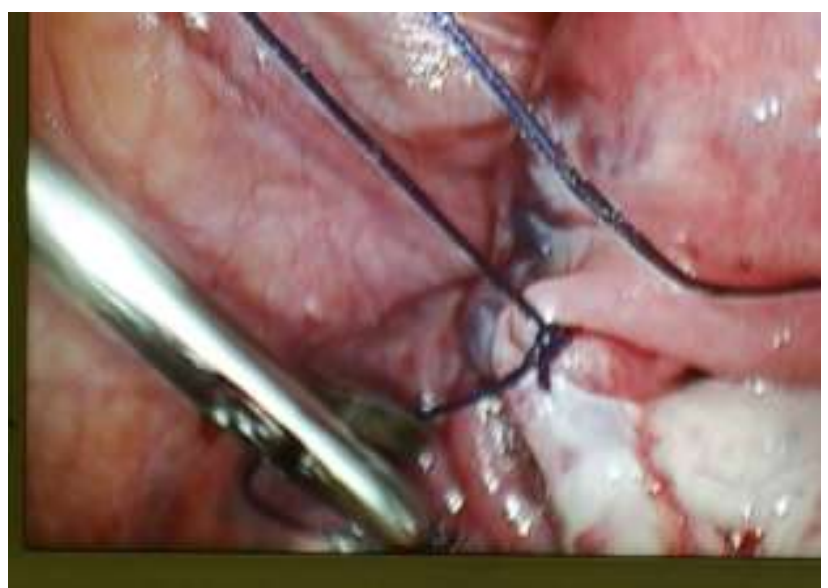

Figure 2: Procedure done

1) Detorsion of left ovarian pedicle.

2) Stripping of ovarian cyst wall.

3) Plication and shortening of left ovarian ligament.

4) Ovariopexy by fixing ovary to anterior abdominal wall near internal inguinal ring with non absorbable sutures.

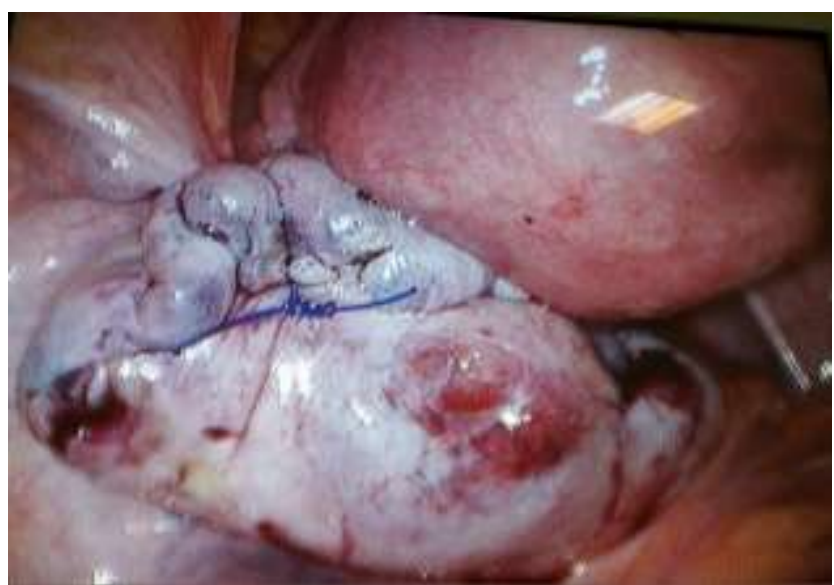

Figure 3: Post op picture

1) Shortened left ovarian ligament

2) Ovariopexy anteriorly at internal inguinal ring

Volume 6 Issue 12, December 2017 www.ijsr.net 


\section{International Journal of Science and Research (IJSR) \\ ISSN (Online): 2319-7064}

Index Copernicus Value (2016): 79.57 | Impact Factor (2015): 6.391

\section{Discussion}

Ovarian torsion has an incidence of $3 \%$ among the acute gynaecological admissions and is frequently missed at first presentation. $^{2}$

The advantages of ovarian preservation are clear as adnexal torsion occurs most often in adolescent girls and women of childbearing age. Detorsion of adnexa helps to preserve ovarian function and maintain fertility. It reduces the risk of premature ovarian failure and the ensuing complications. After detorsion, even if ovarian masses look haemorrhagic and friable, ovarian function has been found to be preserved, as shown by follicular development on ultrasound, subsequent unrelated laparotomy and fertilization at IVF $^{3}$.

Here in this case patient already had underwent right salphingoophorectomy in view of torsion. Patient has tendency of recurrent torsion. This time also patient presented with torsion in the second ovary. This time it was of utmost importance to preserve the ovarian function to prevent surgical menopause and to maintain the reproductive function.

Ovariopexy for ovarian torsion is easily done by many methods. Such as suturing to the lateral pelvic wall, plication of the ovarian ligament or even fixation to the back of the uterus, but it is little difficult to do it for pregnant women with less manipulation. ${ }^{4}$

Sonography is usually not reliable in the diagnosis or exclusion of this entity ${ }^{5}$. In some patients, torsion can recur without obvious pathology. Oophoropexy after surgical detorsion has become an acceptable management option for girls with idiopathic recurrent ovarian torsion. Unlike cases of testicular torsion in males for which surgical detorsion and pexy of testes is the standard of care oophoropexy is not performed as often after detorsion of the ovary, but could be considered for prevention of recurrence. ${ }^{6}$

\section{Conclusion}

Though recurrent ovarian torsion is not very common, when it does occur, it is very serious problem. Emergency measures are required not only to relive symptoms but also to save ovary function. One will come across an occasional case where the other side ovary has been removed for some other indication on a previous occasion.

Dealing with the rotated remaining ovary becomes a challenge especially in young women interested in future fertility. A simple single approach of detorsion is not sufficient and leaves the patient vulnerable to repeat torsion. At least one approach to fix this detorsioned ovary is recommended. Fixing it snugly to an avascular neighbouring structure is a good method. Additional shortening of the round ligament by plication ensures that the ovary is fixed on both ends and cannot pivot about its axis on any future occasion.

Such a multipronged approach improves prognosis of the patient for menstrual as well as reproductive function.

\section{References}

[1] WhiteM,StellaJ.Ovariantorsion: 10-year perspective. Emerg MedAustralas.2005Jun;17(3):231-7.

[2] Walid MS, Heaton RL. Chronic Ovarian Torsion Treated Laparoscopically. Proc Obstet Gynecol. 2011 Apr;1(3):Article 1[3 p.]. 2010 December

[3] Ruby Hall IVF and Endoscopy Center, Ruby Hall Clinic, Pune, India Sunita Tandulwadkar, Ruby Hall IVF \& Endoscopy Center, Ruby Hall Clinic, Pune., India. J Gynecol Endosc Surg. 2009 Jan-Jun; 1(1): 21-26.

[4] Oelsner G, Cohen SB, Soriano D, Admon D, Mashiach S, Carp H. Minimal surgery for the twistedischaemic adnexa can preserve ovarian function. Hum Reprod. 2003;18:2599-602. [PubMed]

[5] Oltmann SC, Fischer A, Barber R, Huang R, Hicks B, Garcia N. Cannot exclude torsion--a 15-year review. Pediatr Surg. 2009 Jun;44(6):1212-6; discussion 1217.

[6] Erin K. Fee, Rula V. Kanj*, Holly R. Hoefgen Recurrent ovarian torsion in an adolescent after oophoropexy Journal of Pediatric Surgery Case Reports 19 (2017) $22 \mathrm{e} 24$ 